\title{
Why Do Firms Use Incentives That Have No Incentive Effects?*
}

\author{
Paul Oyer \\ J.L. Kellogg Graduate School of Management and \\ Institute for Policy Research \\ Northwestern University
}

January 2000

\begin{abstract}
Firms often pay individuals for group-level, industry-level, or even economy-wide performance when agency theory suggests these contracts provide minimal incentive and lead to inefficient risk bearing. This paper derives a simple model of why firms might choose to implement stock options, profit sharing, and other pay instruments that reward (or penalize) "luck." The model relies on two key assumptions: 1) adjusting the terms of employment contracts is costly to the firm, and 2) agents' outside opportunities are not constant. I explore how firmperformance-based pay will respond to variation in risk aversion, workers' reservation utility, and the correlation between a firm's performance and that of the economy as a whole. I also discuss how the model fits with widely distributed stock options (especially in risky businesses such as high technology), executive compensation, and profit sharing. The model suggests that, while agency theory has focused on incentive compatibility, the often overlooked participation constraint can help explain many common compensation schemes.
\end{abstract}

*I thank Kenneth Corts, Robert Gibbons, James Rebitzer, and Scott Schaefer for helpful discussions. poyer@nwu.edu, phone: 847-467-3790. 


\section{Introduction}

Many compensation plans reward or punish agents for factors they cannot control, but do not provide strong incentive effects. An often-discussed example of this phenomenon is executive compensation (where stock options are not generally indexed to the overall market). But many firms also offer firm-wide stock options and profit sharing plans that provide even less incentive than executive plans - after all, most workers can expect to reap a very minimal amount of personal gain from their contribution to firm value or profits. Given the free-rider problems in group compensation plans, why are they so prevalent? Standard explanations include behavioral reasons (morale, teamwork, norms, etc.) and, in some cases, tax considerations. I consider an alternative and largely rational explanation that reconciles standard agency models with profit sharing. ${ }^{1}$

Where much of the previous agency literature has concentrated on inducing optimal effort, I consider the importance of the generally overlooked participation constraint. I study a model where agents' outside opportunities are correlated with firm profits or stock price and where both turnover and adjusting the pay scheme parameters are costly. Given these assumptions, the firm may find it efficient to pay the agent in a way that is correlated with the outside options presented by the outside labor market (despite the requisite risk premium) rather than pay a fixed wage that insures participation in all states.

The model derived below starts from the assumption that wage adjustments are costly, but workers are willing to make part of their pay contingent on firm performance if they are compensated for the corresponding risk. The agent gets an outside offer each period that is based on the state of the economy. The firm can choose to pay a fixed wage that ensures participation in all states, but this would necessitate paying rents to the worker when outside opportunities are less lucrative. It could also choose to adjust wages to market wages, though doing so may lead to information gathering, negotiation, and turnover costs. Alternatively, the firm can make some level of pay contingent on the firm's realization of profits. These profits are imperfectly correlated with the economy. Pay based on firm performance will not, ex post, be the same as the worker's outside opportunity, thereby passing some risk along to the employee. The firm has to find the right tradeoff between the risk premium of variable pay and the rents associated with a fixed wage. The firm can opt to use a spot labor market if these costs become too onerous, though it incurs other transaction costs if it chooses to do so.

This paper aims to formalize a model of why firms might choose profit sharing or other incentives based on firm-wide performance (even if those incentives have no effect on the actions of employees)

\footnotetext{
${ }^{1}$ I will use the term "profit sharing" to refer to any compensation plan based on a large group's performance.
} 
and to consider factors that may affect the adoption and importance of such plans. I do not mean to suggest that this "stabilization" effect of profit sharing is a new idea. The model is similar in many ways to the Weitzman (1984) share economy, but I focus on optimal firm choices (instead of social planning), voluntary turnover (instead of displacement), and reconciling the real world with agency theory (rather than attempting to prescribe policy to increase macroeconomic welfare.) Also, the model in this paper formalizes much of the intuitive discussion (and is consistent with the empirical findings) of sharecropping in Alston and Higgs (1982).

Thomas and Worrall (1988), Harris and Holmstrom (1982), and Beaudry and DiNardo (1991) also formulate models where wages are sensitive to market rates and firms have to balance compensation and turnover costs. Thomas and Worrall (1988) and Harris and Holmstrom (1982) derive models of how firms might adjust their pay systems to market forces, while insulating agents from much of the risk. Their models, however, assume that contracts can be readily adjusted to compete with spot market wages and, as a result, do not lead to pay being a function of firm performance. Beaudry and DiNardo (1991) also derive a model with wages that adjust upwards to market forces. But they do not consider the amount of (or even the possibility of) contingent pay.

Lazear's (1999) model is similar to the model in this paper in that it addresses the issue of why firms would want to make pay sensitive to firm performance if that pay has no effect on agents' actions. His model justifies this practice when a firm wants to extract information from an agent. However, as Lazear (1999) mentions (and as I discuss in Section 5.1 below), this model cannot explain profit sharing and stock option plans that are available to a large number of employees.

The rest of the paper proceeds as follows. Sections 2 and 3, respectively, describe the model and three possible types of equilibrium contracts. Section 4 analyzes compartive statics. I explore how the decision whether or not to make pay a function of firm performance and, if relevant, the amount of firm-performance-based pay are affected by such factors as the correlation between the firm's success and market wages, the variance in workers' reservation wage, and agents' risk aversion. I consider how consistent the model is with stock option schemes, executive compensation contracts, and traditional profit sharing in Section 5. I discuss the model's ability to explain a pay phenomenon that is at odds with previous agency theories - the high level of stock options in risky industries such as the technology sector. Finally, Section 6 summarizes and discusses possible extensions. 


\section{The Model}

A risk neutral firm hires a risk averse worker. Effort is verifiable and contractible. The worker's utility is $U=E[$ wages] $-r \operatorname{Var}[$ wages] less any transaction costs of renegotiation or switching jobs. Gross profits (that is, before agent compensation) are $\theta$ if there is a worker during the production phase, so profits are $\theta$ less payments to the worker. The game unfolds in the following four stages (see timeline in Figure 1):

1. The firm offers a contract to the worker that specifies a fixed wage $(w)$ and a share of firm gross profits $(b)$. If the worker accpets the contract, both parties prepare for production.

2. The worker receives an outside offer of either $s_{h}$ or $s_{l}$ (where $s_{h}>s_{l}$.) $\left(s_{h}\right.$ and $s_{l}$ may be correlated with $\theta$, as described below.)

3. By incurring costs of $k$, the firm can either adjust the terms of the contract or, if the worker leaves, replace the worker at a wage of $s_{h}$ or $s_{l}{ }^{2}$

4. Production takes place, $\theta$ is revealed, and contracts are settled.

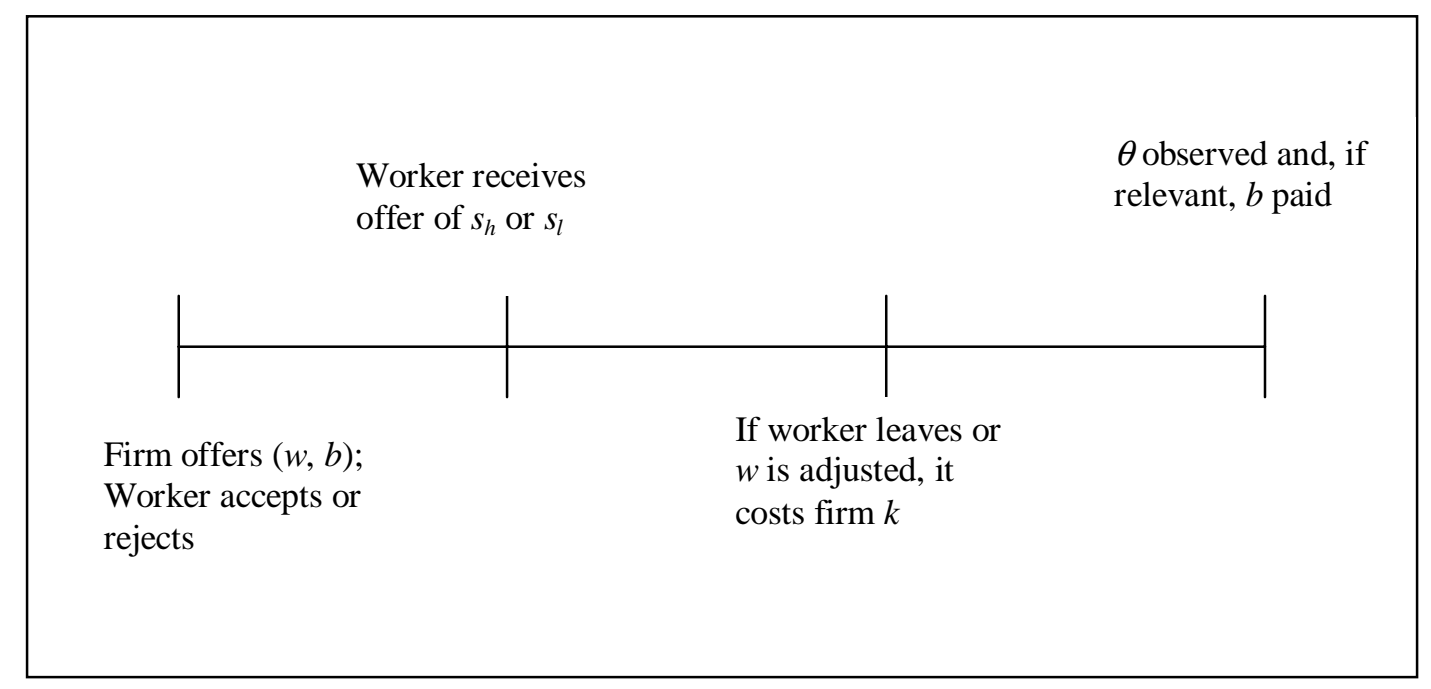

Figure 1: Timeline

Though $\theta$ is not revealed until the end of the game, the outside offer $\left(s_{h}\right.$ or $\left.s_{l}\right)$ acts as a signal and is revealed to all parties. Properties of the signal and, given the signal, the expected value of $\theta$ include

\footnotetext{
${ }^{2}$ The costs may reflect the opportunity cost of search, loss of specific human capital acquired during the preparation stage, and/or the costs of learning the current reservation wage.
} 
1. $\operatorname{Pr}\left(s=s_{h}\right)=q$

2. $\operatorname{Pr}\left(\theta=\theta_{h} \mid s=s_{h}\right)=p_{h}$

3. $\operatorname{Pr}\left(\theta=\theta_{h} \mid s=s_{l}\right)=p_{l}$

Note that, as long as $1>p_{h}>p_{l}$, there are two points where uncertainty is reduced. In stage two, the signal provides an improved, though imperfect, estimate of gross profits. In stage four, actual gross profits are revealed and all uncertainty is resolved. Define $p$ to be the unconditional probability of high gross profits (that is, $\operatorname{Pr}\left(\theta=\theta_{h}\right)=p$.) The above properties of the conditional probabilities of high gross profits $\left(p_{h}\right.$ and $\left.p_{l}\right)$ and the probability of a favorable signal imply

$$
p=q p_{h}+(1-q) p_{l}
$$

The firm can pay the worker, either in part or in full, through a fixed wage of $w$. $w$ cannot be made conditional on the signal when the contract is initially written, nor can $w$ be costlessly adjusted to reflect the signal once it is revealed. The firm can pay a fixed wage of $s_{h}$ in order to guarantee the agent's participation in either state or the parties can write a contract based on the value of $\theta .^{3}$ So an employment contract consists of one or both of a fixed wage $(w)$ paid in all states and a bonus (b) paid in the event that $\theta=\theta_{h} \cdot{ }^{4}$ In order to insure participation regardless of the signal, the pair $w$ and $b$ must meet two participation constraints. If $s=s_{h}$, then the worker will stay with the firm if

$$
s_{h} \leq w+b p_{h}-r b^{2} p_{h}\left(1-p_{h}\right)
$$

Similarly, if $s=s_{l}$, then the worker will stay if

$$
s_{l} \leq w+b p_{l}-r b^{2} p_{l}\left(1-p_{l}\right)
$$

The firm can use two different strategies to make both participation constraints bind. First, it can adjust the wage to exactly meet the outside offer after the signal is revealed. Alternatively, it

\footnotetext{
${ }^{3}$ One way to make the assumptions less extreme is to assume workers receive a random draw from an outside offer distribution where the outside offer distribution is related to the signal. Then the firm would have to choose its wage and bonus so as to minimize costs of compensation, loss of employees, and, possibly, renegotiation costs.

${ }^{4}$ By assuming pay can only be made contingent on $\theta$, I am assuming that, among the measures the agent is willing to contract on, this is the measure that is most correlated with the signal. This could be because workers will not accept contracts with some portion of pay based on a stock market or industry index, the firm's success is more indicative of the worker's reservation wage than a broader measure, or the bargaining costs to define the proper index are so great that the firm and agent agree to contract on $\theta$.
} 
can select a positive $b$ such that the agent earns her reservation wage in expected value, regardless of the signal. Both of these choices impose some costs on the firm, however, so it may prove profitable to pay the employee in such a way that her participation constraint does not always bind. Each possible outcome is discussed in the next section.

\section{Three Possible Outcomes}

\subsection{Spot Labor Markets}

The firm may offer a wage of $s_{l}$ and then spend $k$ to adjust the wage up to $s_{h}$ if the more favorable signal is observed. In such circumstances, the firm is transacting in a spot labor market. The firm pays no risk premium or rents to the worker, but it sometimes incurs the transaction costs of changing wages. The profits of a spot labor market strategy are gross profits minus wages ${ }^{5}$ minus transaction costs. Expected gross profits, which are not affected by the employment contract, are $p \theta_{h}$. Wages are $s_{h}$ when a good signal is observed (which occurs with probability $q$ ) and $s_{l}$ when the low signal is observed. Transaction costs are $k$ times the probability that wages have to be adjusted (which occurs when a high signal is observed.) ${ }^{6}$ This occurs with probability $q$. Profits in a spot market regime can therefore be expressed

$$
\Pi=p \theta_{h}-q s_{h}-(1-q) s_{l}-q k .
$$

(4) applies when the firm uses spot markets and no profit sharing. This is the highest level of profits if the firm uses spot markets, since the firm is paying no risk costs and no rents. If the firm were to add an element of profit sharing, it would not save any adjustment costs, but would incur risk or rent sharing costs.

\subsection{Dual Binding Participation Constraints (DPC)}

Spot markets lead to potentially substantial transaction costs. The firm can avoid these costs, and keep all the surplus from the relationship, if it chooses $w$ and $b$ such that, for both realizations of the signal, the employee is exactly indifferent between staying at the firm and leaving. That is, the

\footnotetext{
${ }^{5} \mathrm{I}$ am assuming that the firm prefers to keep operating, even when the low signal is observed, either because it is still profitable or continuity is valuable.

${ }^{6}$ The firm may prefer to set the wage to $s_{h}$ and lower it when an unfavorable signal is observed. But, even when that is optimal, it has no effect on the following results, so I ignore the possibility of wage decreases.
} 
firm can choose the wage and a share of profits such that (2)-(3) hold with equality. Combining equations (2) and (3) yields

$$
s_{h}-s_{l}=b\left(p_{h}-p_{l}\right)-r b^{2}\left[p_{h}\left(1-p_{h}\right)-p_{l}\left(1-p_{l}\right)\right] .
$$

I impose the following assumption to make the analysis more tractable:

$$
p_{h}+p_{l}=1
$$

An example of this special case is when the unconditional probabilities of both the high state and the high signal are $\frac{1}{2}$ (that is, $q=p=\frac{1}{2}$.) This simplifies the analysis by making the expected risk unrelated to the signal. ${ }^{7}$ Given (6), (5) implies that the optimal bonus is

$$
b=\frac{s_{h}-s_{l}}{\left(2 p_{h}-1\right)}
$$

The bonus increases with the difference between the two possible reservation utilities because the firm wants to lower the base wage it has to pay in the low signal state. Also, the bonus decreases as the difference between the probabilities of the good state prevailing under the two signals increases, so as to keep total expected bonus payments constant. However, these comparative statics results rely on any changes to the exogenous parameters not changing which type of equilibrium holds. Changes could lead to a new equilibrium where the bonus no longer solves (7).

In a case where two participation constraints bind (DPC hereafter), profits and the guaranteed wage are

$$
\begin{gathered}
\Pi=p \theta_{h}-s_{h}+\left(\frac{s_{h}-s_{l}}{p_{h}-p_{l}}\right)\left(\left(p_{h}-p\right)-\left(\frac{s_{h}-s_{l}}{p_{h}-p_{l}}\right) r p_{h}\left(1-p_{h}\right)\right) \\
w=s_{h}+\left(\frac{s_{h}-s_{l}}{p_{h}-p_{l}}\right)\left(\left(\frac{s_{h}-s_{l}}{p_{h}-p_{l}}\right) r p_{h}\left(1-p_{h}\right)-p_{h}\right)
\end{gathered}
$$

\footnotetext{
${ }^{7}$ This assumption makes the calculations and discussion that follow much simpler, with no apparent effects on the results. I relaxed this assumption and then solved for the optimal contract and for which type of equilibrium would prevail using many parameter sets. I then determined how the contract and type of equilibrium changed when the main parameters of interest varied. The results were entirely consistent with the results in the rest of the paper, with a minor exception that is noted in Section 4.3.
} 
The term that includes $r p_{h}\left(1-p_{h}\right)$ in wages and profits represents the risk premium necessary to induce the worker to accept a given level of profit sharing. If this risk cost is prohibitive, the firm may choose to use spot markets (see previous section) or it may choose not to keep the worker bound by her participation constraint in all states (as discussed in the following section.)

\subsection{Single Binding Participation Constraint (SPC)}

The previous subsections considered two ways the firm can extract all the surplus from its relationship with the agent. However, these strategies lead to either transaction costs (spot markets) or compensating the worker for risk (DPC.) There may be situations where the firm is better off with a less extreme strategy. If the firm sets $w$ and $b$ so as to maximize profits while insuring the worker's participation when the signal is high, the firm may choose to pay rents to the worker when the signal is low. This is because, were the firm to drive the worker down to her participation constraint given a low signal, it would have to pay her more in risk premium than the expected rents if the worker is overpaid when the signal is low. I refer to an equilibrium where a single participation constraint binds as an SPC equilibrium. ${ }^{8}$

Note that the firm can avoid all transaction and risk costs by setting $w=s_{h}$ and $b=0$. Such a contract would satisfy (2) exactly and enable the agent to earn rents of $s_{h}-s_{l}$ in periods where an unfavorable signal is observed. However, the firm may be able to save some of these rents by passing along some of the risk to the agent.

The firm will choose $b$ (or $w$ ) so as to maximize $\Pi=p\left(\theta_{h}-b\right)-w$, subject to (2) holding with equality. After generating the first-order condition and rearranging terms, the optimal bonus can be written

$$
b=\frac{p_{h}-p}{2 r p_{h}\left(1-p_{h}\right)}
$$

Some simple comparative statics emerge from (10). The optimal bonus is decreasing in $p$ and increasing in $p_{h}$ since a decrease in $p$ or an increase in $p_{h}$ makes the signal less informative and, therefore, transfer more risk to the agent. If both $p$ and $p_{h}$ increase by the same amount (that is, if the signal gets no better, but the good state becomes more likely), then the optimal bonus increases if $p_{h}>\frac{1}{2}$ and decreases if $p_{h}<\frac{1}{2}$. This is because the variance of the performance measure is increasing until $p_{h}$ reaches $\frac{1}{2}$. The bonus is also decreasing in $r$, since, if the agent is more risk averse, the firm should shoulder more of the risk.

\footnotetext{
${ }^{8}$ It is trivial to show that the firm would never offer a contract where the participation constraint only binds when the low signal is observed.
} 
After some simple manipulation, profits and the guaranteed wage in an SPC equilibrium can be expressed

$$
\begin{gathered}
\Pi=p \theta_{h}-s_{h}+\frac{\left(p_{h}-p\right)^{2}}{4 r p_{h}\left(1-p_{h}\right)} \\
w=s_{h}+\frac{p^{2}-p_{h}^{2}}{4 r p_{h}\left(1-p_{h}\right)}
\end{gathered}
$$

The profit and wage terms now includes both a risk premium and rents that the worker receives if the signal is unfavorable. The relative importance of transaction costs, rents, and the risk premium determine the optimality (and feasibility) of each of the three possible contract types, as discussed in the next section.

\subsection{Which of the Three Possibilities Will Hold?}

When does the optimal contract make just one participation constraint bind (i.e., solve (10)) and when does it make both constraints bind (i.e., solve (7))? If (3) holds when $b$ is the optimal SPC bonus (i.e.,(10)), an SPC regime will hold. This is because, in order to get the other participation constraint to bind, $w$ would have to be lowered and $b$ would have to increase. But any change in the bonus from (10) lowers profits and the firm will prefer to pay the worker the necessary rents rather than impose additional risk on the agent. However, if the bonus is as in (10), but (3) does not hold, then an SPC equilibrium is not feasible. In this case, the firm prefers to pay the full risk premium necessary to get both participation constraints to hold with equality to sharing some of the surplus with the worker.

By combining (2) and (3), substituting the bonus from (10), and rearranging terms, I find that an SPC equilibrium dominates DPC when

$$
s_{h}-s_{l}>\frac{\left(p_{h}-p\right)\left(2 p_{h}-1\right)}{2 r p_{h}\left(1-p_{h}\right)} .
$$

(13) captures the conditions under which the risk premium necessary to make the worker's participation constraint bind in all states is so high that the firm would prefer to pay the worker more than her reservation wage in some states. The next section investigates how some of the key parameters affect this trade-off between risk bearing costs and rents.

But the trade-off between risk costs and rents applies only when choosing between the regimes with no adjustment costs (i.e., DPC and SPC.) If the profits under the optimal zero adjustment 
plan are lower than those in a spot market, the firm will opt for the spot market. The firm's preferred contract emerges from combining and comparing the previously derived profit functions for each of the three types of contracts $((4),(8)$, and (11)). Spot markets are preferred to the SPC equilibrium when

$$
-q k-p s_{h}-(1-p) s_{l}>-s_{h}+\frac{\left(p_{h}-p\right)^{2}}{4 r p_{h}\left(1-p_{h}\right)}
$$

and spot markets are preferred to the DPC equilibrium when

$$
-q k-p s_{h}-(1-p) s_{l}>-s_{h}+\left(\frac{s_{h}-s_{l}}{p_{h}-p_{l}}\right)\left(\left(p_{h}-p\right)-\left(\frac{s_{h}-s_{l}}{p_{h}-p_{l}}\right) r p_{h}\left(1-p_{h}\right)\right) .
$$

Note that, since gross profits are unrelated to the type of contract, these conditions simply determine which type of contract yields the lowest labor costs.

The next section investigates how changes in the exogenous parameters (such as the quality of the signal, the reservation wages, and the agent's risk aversion) affect which regime prevails, the optimal level of profit sharing, and the profits of the firm.

\section{Comparative Statics}

\subsection{Signal Quality}

This section considers how the quality of the signal (specifically, $p_{h}$ ) affects the firm's actions. I establish two main results. First, as the quality of the signal improves, the likelihood that the firm will choose to use profit sharing instead of spot markets increases and, if profit sharing is optimal, a better signal induces the firm to lower (and eventually eliminate) the rents it shares. The second (and related) finding is that, as the signal goes from completely uninformative to perfect, the level of profit sharing is likely to be zero for a while, then increase to a peak, and then fall.

Proposition 1 1. If the signal is uninformative, the firm will set $b=0$.

2. The adoption of profit sharing is increasing in signal quality.

3. When profit sharing is optimal, an SPC equilibrium will hold for sufficiently uninformative signals but a DPC equilibrium will hold above some critical signal quality.

4. If the signal is somewhat but imperfectly informative (that is, if $1>p_{h}>p_{l}$ ), then the firm will either use spot markets or some positive level of profit sharing. 
Proof. If $p_{h}=p_{l}$ (that is, if the signal is unrelated to the agent's outside opportunities,) then, since $s_{h}>s_{l},(2)$ can only hold if (3) does not bind. Combining this with the fact that $p_{h}=p$ when $p_{h}=p_{l},(10)$ implies $b=0$. (proof of 1$)$

Since the derivatives of (11) and (8) with respect to $p_{h}$ are positive, increasing the signal quality makes any profit sharing arrangement more profitable. But (4) suggests that any change in $p_{h}$ that does not affect the overall probability of a good outcome or a good signal will not have an effect on spot market prices. (proof of 2)

Consider the case where the signal provides very little information. That is, $p_{h}-p_{l}=\varepsilon$, where $\varepsilon$ is very small, or, in other words $p_{h}=\frac{1}{2}+\varepsilon$. Then the $\lim _{\varepsilon \rightarrow 0} \Pi=-\infty$ in any DPC equilibrium. Now consider a candidate SPC equilibrium. For small enough $\varepsilon, p_{h}$ must be sufficiently close to $p$ that (13) will hold, insuring that the SPC equilibrium is sustainable. Therefore, for $\varepsilon$ small enough, any optimal action by the firm where $b>0$ will be an SPC regime. Now consider the case where $p_{h}=1-\varepsilon$, so the signal is nearly flawless. As $\varepsilon$ gets arbitrarily small, $b$ gets very large and $w$ gets very small at any SPC equilibrium. For sufficiently high $p_{h}$, (3) will be violated and an equilibrium will have to be DPC. (proof of 3)

Allow the signal to convey information, so $p_{h}>p_{l}$, but sufficiently little that an SPC equilibrium holds. Suppose the firm selects the minimum cost contract that retains employees but uses no profit sharing. So $b=0$ and $w=s_{h}$. Then $\Pi=p \theta_{h}-s_{h}$. But switching to a positive bonus would change profits to (11), which would be an improvement. (proof of 4) QED.

The proposition starts by establishing the somewhat obvious, but intuitively appealing, result that the firm would not want to tie the agent's pay to a measure that is not correlated with either output or outside opportunities. At the other extreme, consider the case where the signal is perfect - that is, $p_{h}=1$ and, given the assumption that $p_{h}+p_{l}=1, p_{l}=0$. Then the risk premium disappears and the solution is to pay a fixed wage of $s_{l}$ and a bonus of $s_{h}-s_{l}$ when profits are high. Since profits are only high when the signal is high, workers are paid exactly their reservation wage with no risk premium and no turnover. As part 3 of the proposition shows, for any sufficiently good signal, the firm will not pay the worker any rents.

There can be two transitions in regime as the signal improves from uninformative to perfect from spot markets to SPC to DPC. For very poor signals, profit sharing is a relatively expensive means of retaining workers. In fact, firms may choose to incur wage adjustment costs periodically, rather than pay the necessary rents during bad times or the risk premium workers would demand from profit sharing. When the signal provides very little information, it is more intuitive to restate (14) in terms of which regime has lower labor costs and to use $q$ (which will be very nearly $\frac{1}{2}$ when 


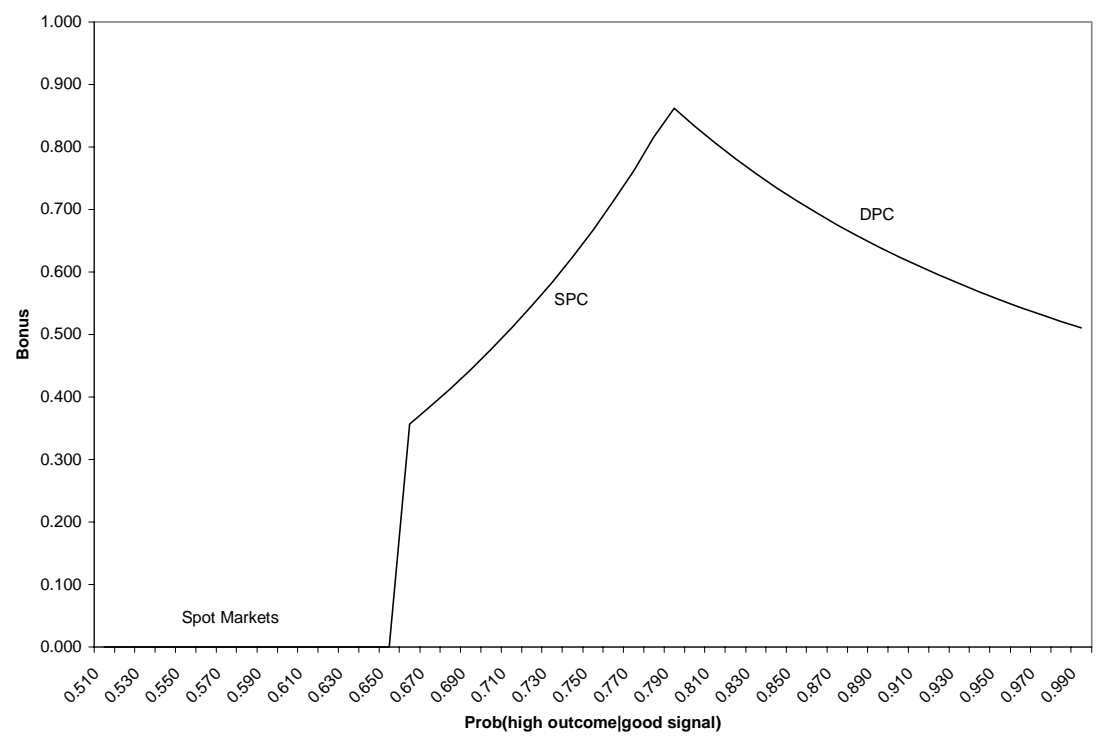

Figure 2: Signal Quality Effect on Bonus

the signal is uninformative.) The firm will use spot markets approximately ${ }^{9}$ when

$$
q k+q s_{h}+(1-q) s_{l}<s_{h}
$$

Intuitively, for a bad enough signal, the firm will opt to use spot markets if the difference between the two reservation wages gets sufficiently big or if the costs of adjusting the wage are small. That is, spot markets become a more attractive option when the firm faces a relatively uninformative signal, when $s_{l}$ decreases (holding $s_{h}$ fixed), and when $k$ decreases. But as the signal becomes more informative, the risk premium decreases. The firm may decide to pay a risk premium and some rents to the worker in a SPC regime rather than pay the adjustment costs associated with using spot markets.

The second transition can occur as the signal improves when the firm is in an SPC state. A better signal leads the firm to use a higher level of profit sharing at a lower premium, driving the worker to be bound by the lower participation constraint. The logical next step intuitively, then, might be to think that the bonus (i.e., the amount of profit sharing) is increasing monotonically in the quality of the signal. But, as shown below, this need not be the case.

Proposition 2 The agent's expected bonus is increasing in signal quality in an SPC state and

\footnotetext{
${ }^{9}$ I say "approximately" because the following condition does not include a term that approaches zero as $\varepsilon$ approaches zero.
} 


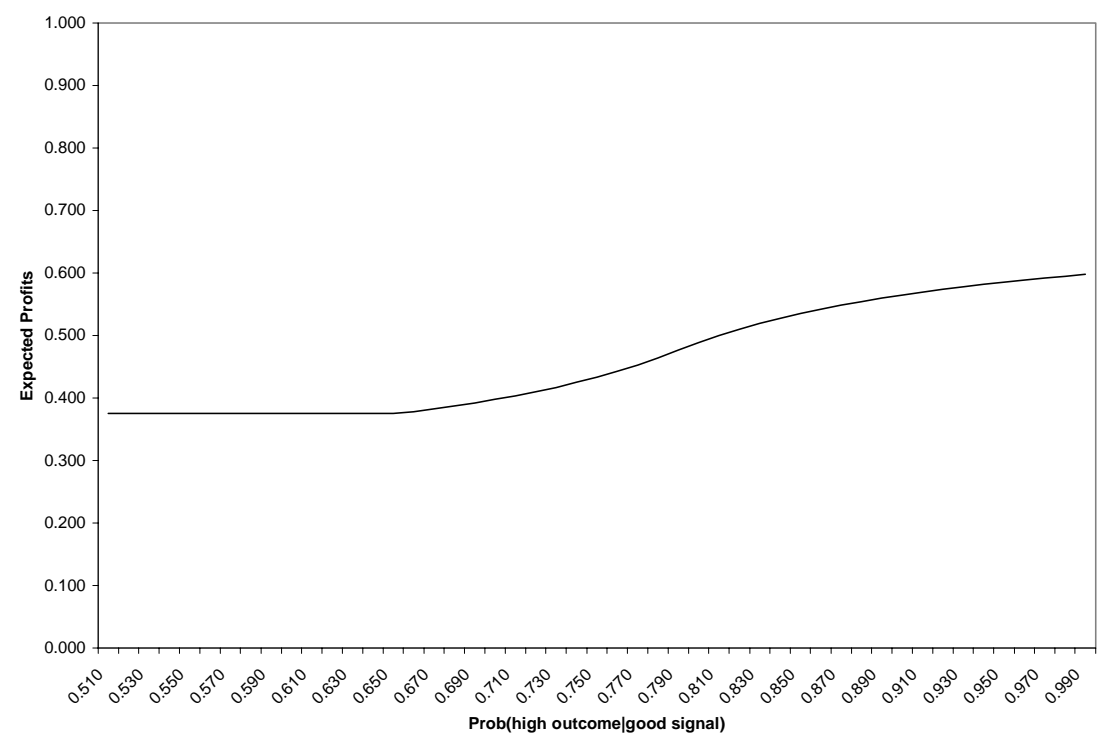

Figure 3: Signal Quality Effect on Profit

decreasing in signal quality in a DPC state. In either state, profits are increasing in signal quality. The guaranteed wage is decreasing in signal quality in any SPC and is increasing in signal quality above some threshold $p_{h}$ in a DPC state.

The proof follows from simple comparative statics and is omitted. The proposition suggests that the optimal level of profit sharing takes an interesting course in the case where the firm transitions from spot market to SPC to DPC as signal quality improves. Specifically, the firm engages in spot markets with no profit sharing for poor signals because the turnover costs are outweighed by the risk sharing and rents necessary to retain employees. Then profit sharing (b) takes a discrete jump up upon reaching some level where the firm switches to a SPC regime. Profit sharing continues to increase with signal quality because the employee is willing to bear more of the risk as the signal gets better.

But then the bonus hits a point where the lower participation constraint binds and the only profit sharing equilibrium is DPC. As the signal improves within a DPC regime, the firm lowers the bonus because the necessary risk premium gets smaller as the signal gets better. This decrease in contingent pay as idiosyncratic risk decreases distinguishes the model from standard agency models that predict a universally positive correlation between risk and incentive pay. As discussed in Section 5.1, this may explain why firms in relatively risky industries are relatively likely to offer stock options to all employees. An example of this non-monotonic effect of signal quality on profit 
sharing is shown graphically in Figure $2 .^{10}$

Figure 3 shows the monotonic rise in profits as the signal improves and once profit sharing takes over from spot markets. This monotonic relationship results from the rents paid to the agent decreasing in signal quality in the DPC regime and the risk premium paid to the employee decreasing in signal quality in the SPC regime.

\subsection{Variance in Reservation Utility}

While the quality of the signal is an important consideration, the signal is irrelevant if the worker's reservation utility is invariant. So this section considers how the firm responds to changes in the variance of the worker's outside options ("reservation variance"), which is captured in the model by $s_{h}-s_{l} .{ }^{11} \mathrm{I}$ establish three main results. First, as reservation utility becomes more variable, the firm is likely to transition from a DPC regime to an SPC regime and, ultimately, to spot markets. Second, as reservation utility becomes more variable, profit sharing increases to a plateau, then stays constant before returning to zero for high enough variance. Third, profits are weakly decreasing in reservation variance.

Proposition 3 1. Unless spot markets dominate for all levels of reservation variance, a DPC regime will be in place for very low variance.

2. At any reservation variance above some threshold level, spot markets will be optimal.

3. At any reservation variance beyond some threshold level, if profit sharing is optimal, it will be in the form of an SPC equilibrium.

Proof. Assume $s_{h}-s_{l}=\varepsilon$, where $\varepsilon$ is very small. Consider a candidate SPC equilibrium. Then (2) will hold with equality but (3) will not bind. Combining these equations with (10), it must be the case that $s_{h}-s_{l}>\frac{\left(p_{h}-p\right)\left(2 p_{h}-1\right)}{2 r p_{h}\left(1-p_{h}\right)}$. But that cannot hold for small enough $\varepsilon$, so a DPC will prevail. (proof of 1)

The left sides of both (14) and (15) are unaffected by reservation variance. But the right sides of both equations are strictly decreasing in reservation variance. So, for high enough reservation

\footnotetext{
${ }^{10}$ All figures assume $k=0.5$ and $\theta_{h}=3$. When not being used as the varying parameter, $r=1, s_{h}=1.25$, $s_{l}=0.75$, and $p_{h}=0.75$.

${ }^{11}$ Increases in reservation variance refer to increases in $s_{h}-s_{l}$ that preserve the mean reservation utility. Given the assumptions of the model, increases in variance occur through an exactly equal increase (decrease) in $s_{h}\left(s_{l}\right.$.) If the $p_{h}+p_{l}=1$ assumption were relaxed, any increase in $s_{h}$ would be coupled with a $\frac{q}{1-q}$ decrease in $s_{l}$.
} 
variance, (14) and (15) must both hold and spot markets will be strictly preferred to retaining workers. (proof of 2)

The proof of part 3 follows directly from (13). Q.E.D.

The proposition establishes that profit sharing becomes a bad strategy if the variance in reservation utilities is extreme. This is because high variance in outcomes leads, ultimately, to higher rents paid to the agent in slow times. It is rents, rather than a risk premium, that lead to spot markets, since the firm always has the option of just paying the high reservation utility in all states and, thus, can eliminate the risk premium. It is never in the firm's best interests to do this, however, since some level of risk premium always pays for itself in lower rents.

The proposition also shows that, to the extent profit sharing dominates spot markets, a DPC will be in place for low enough reservation variance since the agent can be held to her indifference point in all states without much of a risk premium. But beyond some threshold reservation variance, it is worth paying the rents in an SPC regime rather than impose the risk costs needed to make the agent's participation constraint bind in all states. Taken together, these clauses of the proposition suggest that, as the reservation variance increases from zero to extreme, the firm is likely to transition from a DPC regime to an SPC regime to spot markets. I now explore the profit and profit sharing implications of this evolution.

Proposition 4 1. Profit sharing (b) is weakly increasing in reservation variance until spot markets become optimal.

2. Firm profits are monotonically decreasing in reservation variance at any profit sharing equilibrium. Profits are convex in reservation variance in a DPC regime and linear in reservation variance in an $S P C$ regime.

Again, the proof follows from simple differentiation and is omitted. The profit result is intuitively simple - increased variance in the agent's outside options leads to either an increase in the risk premium (in a DPC regime) or increased agent rents (in an SPC regime) and therefore lowers the firm's profits. The quadratic risk premium drives the effect on profits in a DPC regime, leading profits to decrease at an increasing rate. But once the regime shifts to SPC, increases in reservation variance cause the firm to pay a constant half unit of rents in bad states for every unit increase in reservation variance.

Profit sharing increases with reservation variance in a DPC regime because more variance in pay is required to keep the worker on both participation constraints as the difference in reservation utility widens. But once the firm lets the lower participation constraint go slack, the optimal trade-off between risk and rents is unrelated to the spread between the reservation utilities. As a 


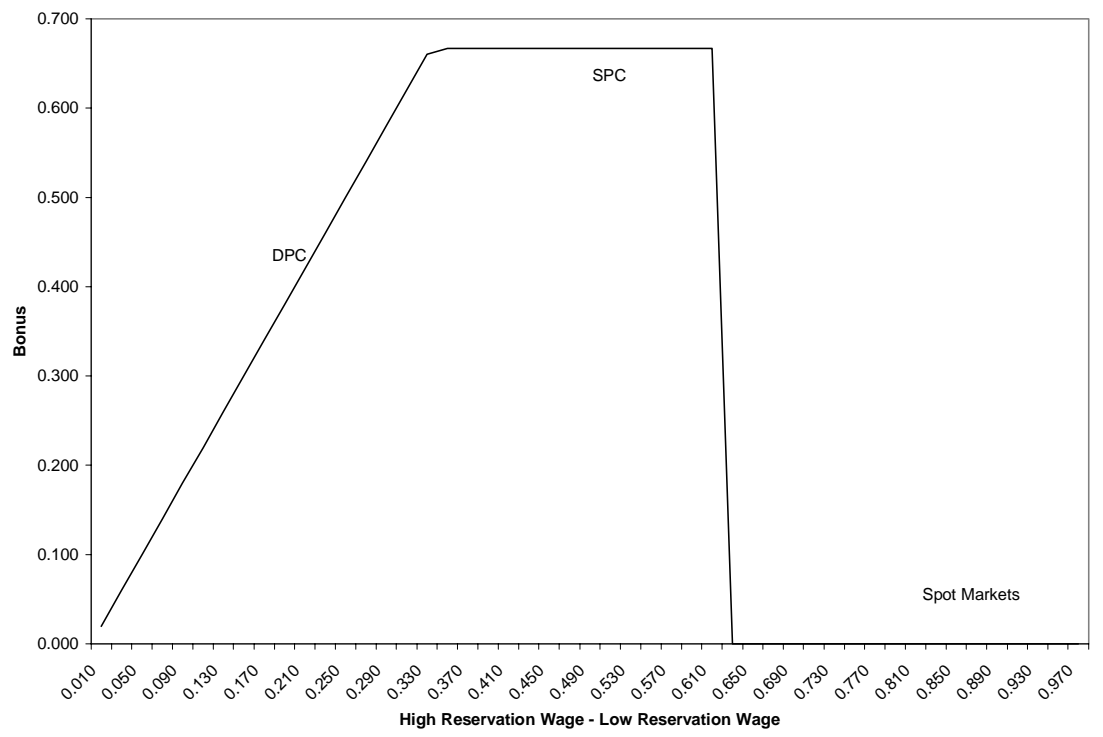

Figure 4: Reservation Variance Effect on Bonus

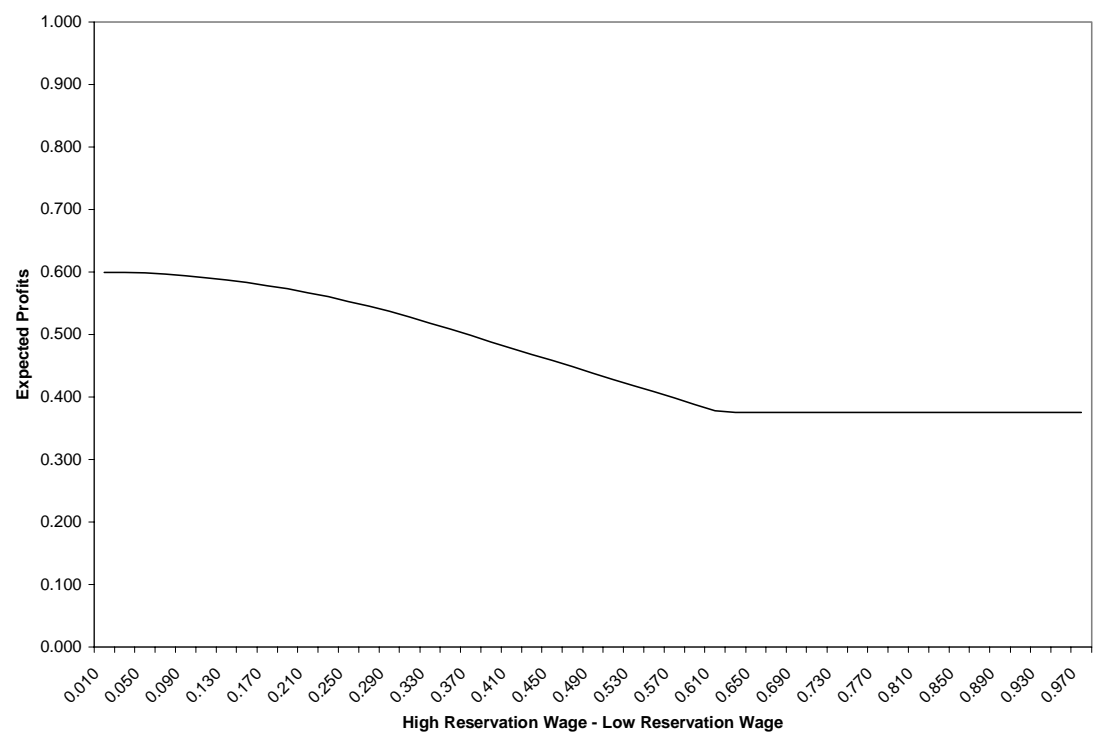

Figure 5: Reservation Variance Effect on Profit 
result, profit sharing increases with initial increases in reservation variance, reaches a plateau, and then is abandoned altogether when the rents overwhelm the adjustment costs associated with spot markets. Figures 4 and 5 graph the effect of reservation variance on profit sharing and profits.

\subsection{Risk Aversion}

The level of agent risk aversion is critical to the model. If the agent is risk neutral, then the firm can insure participation in all states while paying no rents. At the other extreme, an agent whose aversion to risk grows arbitrarily large cannot be efficiently paid through a profit sharing scheme and will either have to earn substantial rents in some states or the firm will face adjustment costs. This section explores how the level of profits and profit sharing evolve for levels of risk aversion between these extremes. I first show that, as risk aversion increases from zero to arbitrarily high, the transitions are similar to those as reservation variance increases - that is, from a DPC regime to an SPC regime to spot markets. I then show the intuitive results that profit sharing and firm profits decrease with risk aversion.

Proposition 5 1. Unless spot markets dominate for risk neutral agents, a DPC regime will be in place for the least risk averse agents.

2. Unless paying a guaranteed wage of $s_{h}$ in all states dominates spot markets, spot markets will be optimal for very high risk aversion levels.

3. At any risk aversion beyond some threshold level, if profit sharing is optimal, the equilibrium will be $S P C$.

The proof follows the same logic as the proof of Proposition 3 and is not drawn out in detail here. The results on risk aversion parallel those for reservation utility since increasing uncertainty has the same effect as an increasing distaste for uncertainty. At low enough levels of risk aversion, the risk premium necessary to keep a worker bound by both participation constraints is not too great and the firm can sustain a DPC equilibrium. But, as the agents gets more risk averse, the risk premium grows relative to the rents that the firm would have to pay the worker if it let the lower participation constraint go slack and, eventually, the firm prefers an SPC equilibrium. Further increases in risk aversion make the risk premium so high that profit sharing may eventually give way to spot markets.

While the transitions among regime type are similar for risk aversion and reservation variance, the effects on profit sharing and profits are somewhat different, as shown in the following proposition. 


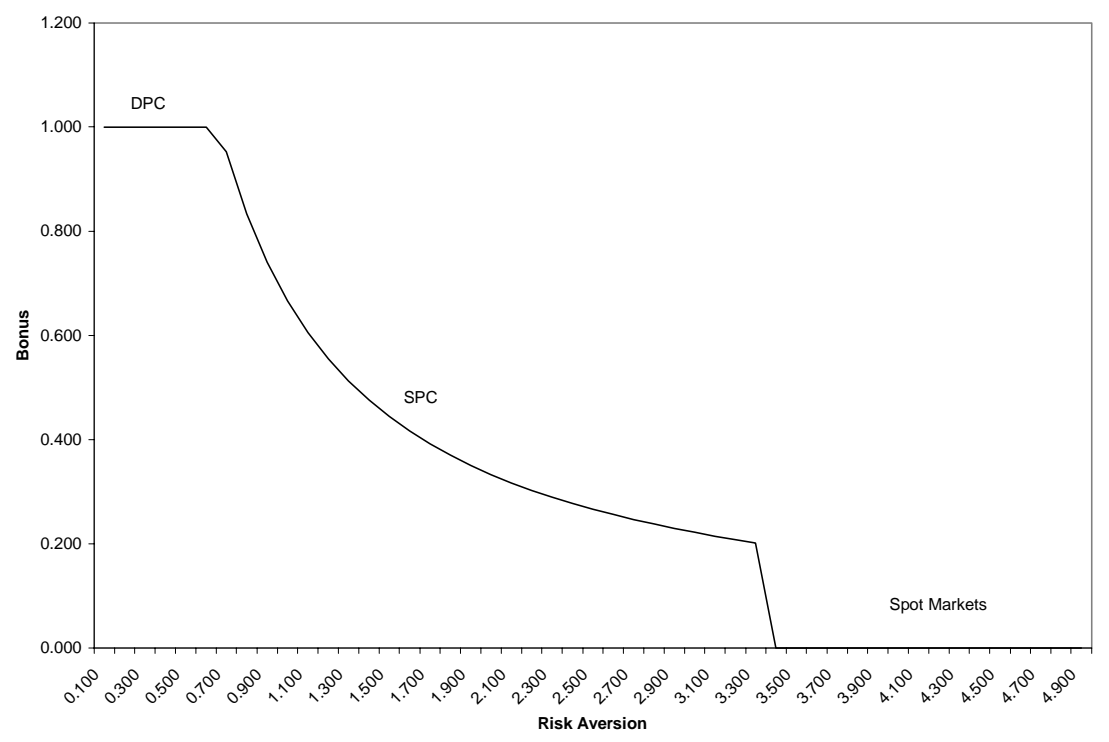

Figure 6: Risk Aversion Effect on Bonus

\section{Proposition $6 \quad$ 1. Profit sharing (b) is weakly decreasing in risk aversion.}

2. Firm profits are monotonically decreasing in risk aversion at any profit sharing equilibrium. Profits are linear in risk aversion in a DPC regime and concave in risk aversion in an SPC regime.

This proof also follows from basic differentiation. The level of profit sharing is not affected by risk aversion in a DPC regime because the risk in both the high and low states is the same. ${ }^{12}$ But, as $r$ continues to increase, the risk premium in a DPC regime eventually becomes sufficiently high that the firm prefers the rents of an SPC to the risk premium needed to keep the agent bound by both participation constraints. Once the SPC regime is in place, further increases in $r$ require further reductions in the bonus as the firm trades even more rents to keep the risk premium in line. Eventually, if the rents are too great, the firm may move to a spot market.

Profits fall monotonically as risk aversion increases. But they fall faster in the DPC regime because the risk premium comes straight out of profits, whereas, once the SPC is in place, the firm can substitute towards rents (and away from risk premium) as $r$ grows further. Figures 6 and 7 graph the effect of risk aversion on profits and profit sharing.

\footnotetext{
${ }^{12}$ This is the only result that I have found to rely on the assumption that $p_{h}+p_{l}=1$. When this assumption is relaxed, the level of risk (and the sensitivity of the bonus to risk) depends on the signal. The optimal $b$ increases (decreases) with $r$ if $p_{h}\left(p_{l}\right)$ is nearer to 0.5 than $p_{l}\left(p_{h}.\right)$
} 


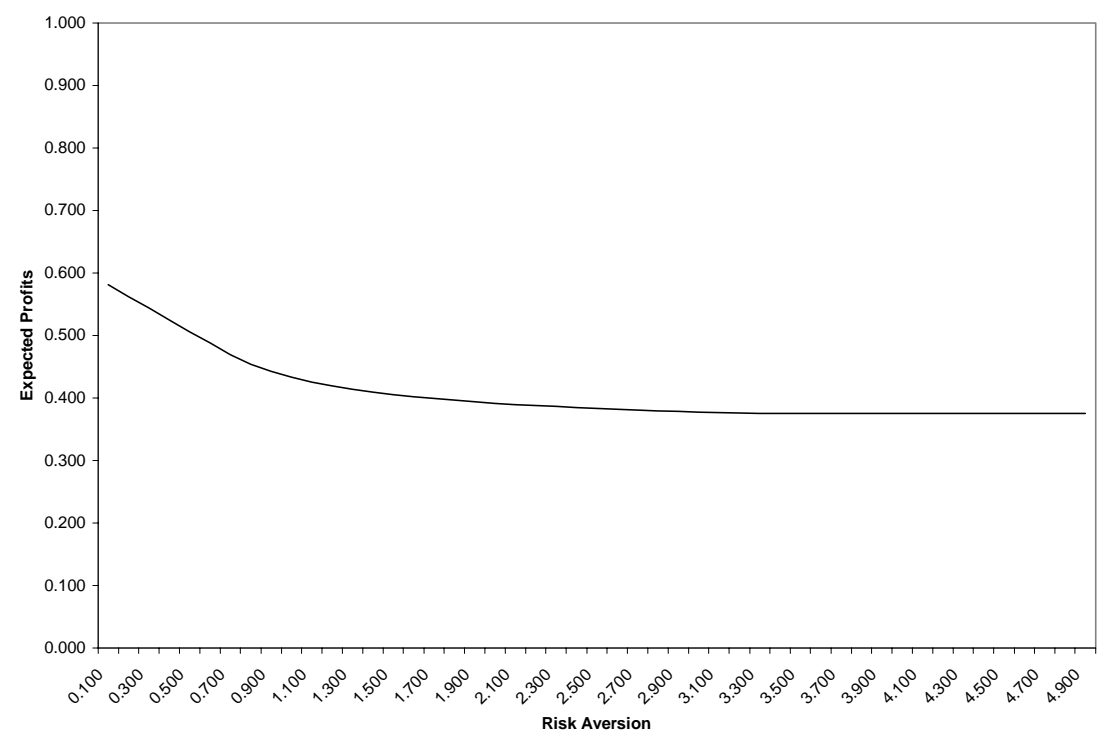

Figure 7: Risk Aversion Effect on Profit

\section{Applications}

\subsection{Employee Stock Options}

High tech companies often give stock options to ALL employees. ${ }^{13}$ At a fledgling "dot com" company, options can have very powerful incentive effects. But it is hard to imagine that most new workers at Microsoft and Cisco Systems, both of which have over 20,000 workers and offer stock options to all of them, believe that their actions affect the value of their stock options. So why do these and other firms offer options as part of their standard compensation plan? One standard justification for stock options is that they vest over a period of time. But many other pay instruments (such as subjective cash bonuses) can be made contingent on continued service without forcing as much risk onto agents. Other common explanations include that the market systematically undervalues the dilution effect of outstanding options, that workers are not as risk averse as commonly believed, and that group-based incentive plans can have a powerful effect on morale. Lazear (1999), after arguing that stock options and other firm-wide incentive plans are not

\footnotetext{
${ }^{13}$ In fact, from 1989-1992, I worked for two different Silicon Valley companies, each of which had approximately 2000 employees. Like everyone else at both companies, I received stock options and, like almost everyone else at both companies, there was virtually no chance that I would have any effect on the price of the companies' stock. One of these companies, 3Com, still offers stock options and profit sharing to all employees, despite its staff having grown to 13,000 .
} 
consistent with incentive effects, suggests that stock options can help firms select on workers with the highest skill. But he concludes that his model "does not explain why some firms give stock options even to very low-level workers."

The model presented above, however, can justify stock options (or other compensation tied to the success of the firm as a whole) for any worker whose outside opportunities are correlated with the success of the firm. That is, if the health of the firm is related to the health of the overall market, and if the state of the overall market is related to initial wage offers, then stock options can be a relatively inexpensive retention device.

Can the model explain the fact that stock options are relatively common and a relatively large part of compensation among growing technology firms? As noted in Section 4.1, a key distinguishing feature of the model is that, at least in a DPC equilibrium, higher idiosyncratic risk (that is, lower signal quality) leads to more contingent pay. Where previous agency models would expect relatively little contingent pay in high-tech companies, the model in this paper can be consistent with observed patterns.

The technology industry, as measured by stock volatility, has traditionally had relatively high variance in the overall fortunes of the industry, which could lead to high reservation variation as firms' demand for labor comes and goes with their markets. This is largely consistent with the discussion in Section 4.2 where I showed that profit sharing is increasing in reservation variance (though profit sharing becomes non-optimal at extreme levels of reservation variance.)

The costs of turnover and lack of labor market frictions also make the model consistent with technology firms using stock options. One might expect that, since there is relatively little firmspecific skill in Silicon Valley and a clustering of similar firms in a small geographic area, the costs to the worker of switching jobs are relatively small. Also, brisk demand for technology workers also makes worker mobility easy while making it hard for firms to replace workers (that is, high $k$.) (14) and (15) suggest that high $k$ make profit sharing (in this case in the form of stock options) profitable relative to spot markets.

Technology markets tend to have relatively young and possibly less risk averse workers (though this is probably endogenous to the compensation contracts). This is consistent with the model's finding that profit sharing will be more common and generally higher (that is, higher $b$ ) when risk aversion is lower, though it also consistent with just about any agency model that considers risk aversion.

Can the model explain the increase in stock based pay over the last few years? ${ }^{14}$ If the tight job

\footnotetext{
${ }^{14}$ The January 18, 2000 Wall Street Journal cites a study by the consulting firm of Watson Wyatt Worldwide that found an increase in the number of employees eligible for stock options, even at lower levels of organizations, between
} 
market of the last few years truly is indicative of high $k$, this could help explain why stock options have become a more widely-used pay instrument. I know of no other systematic changes in the model's parameters $\left(r, s_{h}-s_{l}\right.$, or $\left.p_{h}\right)$ that can tie the stock option trend to the model, however.

\subsection{Executive Compensation}

Are executive compensation contracts consistent with agency theory? That is an often studied and widely argued question. Models of efficient risk sharing typically imply that, wherever possible, executives should be measured on relative, rather than absolute, performance. That is, to the extent that some underlying shock affects performance across multiple firms in a way that individual executives cannot affect, firms will find it profitable to filter this common shock out of the measures of executive performance. ${ }^{15}$ Most executive stock options and other executive incentives do not compensate for market-wide or industry-wide shocks and empirical studies have found little evidence of relative performance evaluation in executive pay. ${ }^{16}$ Reasons given for the lack of indexing in executive pay include tax considerations, simplicity, and the costs and difficulties of identifying an appropriate comparison group. But perhaps one reason relative performance evaluation is not more common is that the models that show it to be optimal typically assume a constant participation constraint.

Bertrand and Mullainathan (1999) analyze the efficiency of CEO incentive contracts, starting with the hypothesis that an efficient contract will reward (punish) high (low) relative performance. They carefully study the oil industry, where common shocks (especially commodity prices) can be easily identified and removed from measures of executive performance. They show that the pay of CEOs of oil companies is affected by oil prices, a factor that is surely beyond the executives' control. They go on to establish evidence of CEOs being rewarded for factors beyond their control in a range of industries. Bertrand and Mullainathan (1999) conclude that "company principals are not fully rationally setting CEO pay."

But the model presented here, with a little relabeling, suggests that it can be optimal to pay CEOs for industry-level performance if industry performance is correlated with the executives' outside opportunities. Suppose that a high oil price (or a high oil futures price) leads to increased

\footnotetext{
1998 and 1999.

${ }^{15}$ Aggarwal and Samwick (1999) and Baker (2000), exploring the distortionary effects of relative performance evaluation noted by Gibbons and Murphy (1990), consider other reasons executive pay should not always be adjusted for peer performance.

${ }^{16}$ Gibbons and Murphy (1990) provide the strongest evidence of relative performance evaluation in executive pay. Murphy (1999) discusses the strength of executive incentives and the lack of indexing.
} 
demand for oil executive talent, either because of entry or because incumbent firms launch new projects. This should raise the demand for, and price of, managerial talent in the oil industry. In the terms of the model, high oil prices cause the probability of success of new ventures to be $p_{h}$ at the same time as they raise a manager's reservation wage to $s_{h}$. Paying the manager for the firm's absolute performance $(\theta)$, rather than it's relative performance $\left(\theta-\theta_{\text {market }}\right)$ could be an efficient way to provide incentives for the manager to work hard while minimizing the chances that she will leave for another oil producer.

Further evidence consistent with the model can be found in the bank CEO market analyzed by Barro and Barro (1990). They find that bank CEO pay is responsive to firm performance but not adjusted for relative performance. So bank CEO compensation is partially based on conditions in the overall banking market. Barro and Barro (1990) also find that bank CEO turnover does respond to relative performance. These facts are consistent with banks letting their compensation schemes fluctuate so as keep pace with market rates, while dismissing executives when firm performance lags peer performance.

\subsection{Traditional Profit Sharing}

Profit sharing plans are common in a variety of industries. ${ }^{17}$ Some firms and economists have justified profit sharing plans on the basis of their incentive effects. According to this argument, employees work harder if they can expect to reap some of the rewards of their efforts. Weitzman and Kruse (1990) argue that profit sharing has at least a mildly positive effect on productivity and profitability. However, Kruse (1993) and Card (1990) argue that the free-rider (or "1/N") problem makes the productivity argument unlikely. Prendergast (1999) and Kruse (1993) suggest that the causality of this relationship is hard to establish. Also, Kruse (1993) points out that no empirical study has found a link between likelihood of profit sharing and number of employees. If profit sharing had incentive effects, I would expect these to dissipate with increases in firm size.

If profit sharing does not have significant incentive effects, why would a firm impose the risk of profit sharing on its employees? The model in this paper, as well as that of Weitzman (1984), justify profit sharing based on what Kruse (1993) calls the "stability theory." When wages are rigid, profit sharing is a means of keeping workers at or near their participation constraints. Kruse

\footnotetext{
${ }^{17}$ Kruse (1993) provides a comprehensive survey of the incidence of profit sharing and economic studies of profit sharing. The model does not apply as well to "gain sharing" and other plans based on improvements of a specific project or initiative within a firm, since the success of such efforts is less likely to be correlated with agents' outside opportunities. But given such plans are implemented endogenously and maybe at least partially in response to competitive wage pressures, they probably fit the general idea at some level.
} 
(1993) suggests that there is some empirical support for this idea, but that it is inconclusive in most studies. He points out that identification of stability effects is difficult given the endogeneity of profit sharing.

Kruse (1993) also suggests that the best predictor of adoption of profit sharing is an increase in profitability of the firm. This is consistent with rent sharing between the firm and workers. But it may also be consistent with the model in this paper. If a firm's prospects improve, the value of retaining workers increases, which increases $k$ in the model. As discussed above, that would increase the value of profit sharing relative to using spot markets. Also note that this contrasts with the empirical implications of Weitzman (1984). While the stability effect of profit sharing in the above model comes from minimizing voluntary turnover, stability in Weitzman (1984) derives from the firm not laying off workers in a downturn. The latter idea would make profit sharing relatively more valuable when the firm's prospects dim.

Another factor that has been found to be correlated with profit sharing is union representation. This, too, could be due to rent sharing. But perhaps the incidence of unions and profit sharing both stem from other causes. Consider the automobile industry, which has historically been heavily unionized and where profit sharing arrangements are common. The automobile industry is subject to significant macro shocks that are common across firms and affect the marginal value of labor. As a result, firm's willingness to pay for labor (and, therefore, worker reservation wages) may have significant variation over time and these movements are probably highly correlated with the firm's prospects. Thus, it may well be the case that signal quality $\left(p_{h}\right)$ is quite high in the automobile industry. In addition, auto workers have significant industry and firm-specific knowledge, which makes turnover costs to the firm $(k)$ relatively high. Though this argument is speculative and anecdotal, it provides a plausible reason for how profit sharing in the automobile industry could be consistent with the model in this paper.

\section{Conclusions and Further Research}

I derived a model that provides a possible reconciliation of agency theory with the fact that agents are often rewarded or punished for things they cannot control. I showed that variability in an agent's reservation utility may lead the firm to want to transfer risk to the worker as a means of insuring participation in various states of the economy. The model relies critically on the assumption that the terms of an agent's compensation scheme are costly to adjust. I also determined that, depending on the parameter values, the firm may find it optimal to pay rents to workers during relatively slow periods and, under certain conditions, may prefer to forsake long-term retention of employees. 
One important feature of the model is that it has some clear empirical predictions. But, on the other hand, predictions are made somewhat ambiguous both by the model's non-monotonic relationships between the amount of profit sharing and certain parameters and by the fact that the model often has opposing implications for a given parameter's effect on profit sharing adoption and the amount of profit sharing a firm will choose. Specific testable hypotheses include:

1. Adoption of profit sharing is increasing in the firm's costs of replacing workers.

2. As signal quality (that is, the correlation between the state of the economy and the prospects for the individual firm) increases, the adoption of profit sharing becomes more attractive. However, when profit sharing is implemented, the effect of signal quality on the amount of profit sharing is ambiguous.

3. As the variation in workers' reservation utility grows, the adoption of profit sharing becomes less attractive. However, when profit sharing is implemented, the higher variation in reservation utility leads to an increase in the amount of profit sharing.

4. Both the adoption and amount of profit sharing are decreasing in employee risk aversion.

I discussed how these predictions match anecdotal and empirical evidence of broad-based employee stock option plans, executive pay schemes, and traditional stock option plans. Though I argued that the evidence is largely consistent with the model's predictions, it may be feasible to test the predictions more rigorously. For instance, one could examine the cross-sectional (and perhaps time-series) variation in profit sharing occurrence and levels using surveys of HR practices, details of bonus plans from consulting firms, and executive compensation contracts.

In addition, there are many ways to enrich the model. For example, the model assumes that separation costs are constant, but they are likely to be dependent on job tenure. Modeling this relationship could lead to interesting findings about the optimal vesting of profit sharing and stock options. Also, a more realistic model might make the possible outcomes $(\theta)$ continuous, rather than just a matter of a high/low state. Finally, it would be interesting to see how the firm would behave if outside offers were drawn from a distribution related to the state of the economy, rather than being perfectly correlated with $s$. This would lead the firm to have to consider the optimal level of turnover, given that it would probably not want to match all outside offers. 


\section{References}

Aggarwal, Rajesh and Andrew Samwick, "Executive Compensation, Strategic Competition, and Relative Performance Evaluation: Theory and Evidence," Journal of Finance, 1999, 54, 1999-2043.

Alston, Lee J. and Robert Higgs, "Contractual Mix in Southern Agriculture since the Civil War: Facts, Hypotheses, and Tests," Journal of Economic History, 1982, 42, 327-353.

Baker, George, "Distortion and Risk in Optimal Incentive Contracts," 2000. Harvard Business School.

Barro, Jason R. and Robert J. Barro, "Pay, Performance, and Turnover of Bank CEOs," Journal of Labor Economics, 1990, 8, 448-481.

Beaudry, Paul and John DiNardo, "The Effect of Implicit Contracts on the Movement of Wages Over the Business Cycle: Evidence from Micro Data," Journal of Political Economy, 1991, 99, 665-688.

Bertrand, Marianne and Sendhil Mullainathan, "Are CEOs Rewarded for Luck?," Working Paper, Princeton and MIT 1999.

Card, David, "Comment on 'Profit Sharing and Productivity'," in Alan S. Blinder, ed., Paying for Productivity, The Brookings Institution, 1990.

Gibbons, Robert and Kevin J. Murphy, "Relative Performance Evaluation for Chief Executive Officers," Industrial and Labor Relations Review, 1990, 43, 30s-51s.

Harris, Milton and Bengt Holmstrom, "A Theory of Wage Dynamics," Review of Economic Studies, 1982, 49, 315-333.

Kruse, Douglas L., Profit Sharing: Does it Make a Difference?, Kalamazoo, MI: W.E. Upjohn Institute for Employment Research, 1993.

Lazear, Edward P., "Output-based Pay: Incentives or Sorting?," Working Paper 7419, National Bureau of Economic Research 1999.

Murphy, Kevin J., "Executive Compensation," in Orley Ashenfelter and David Card, eds., Handbook of Labor Economics, Volume 3, North-Holland, 1999.

Prendergast, Canice, "The Provision of Incentives in Firms," Journal of Economic Literature, 1999, 37, 7-63.

Thomas, Jonathan and Tim Worrall, "Self-Enforcing Wage Contracts," Review of Economic Studies, $1988,55,541-554$.

Weitzman, Martin L., The Share Economy, Cambridge, MA: Harvard University Press, 1984.

and Douglas L. Kruse, "Profit Sharing and Productivity," in Alan S. Blinder, ed., Paying for Productivity, The Brookings Institution, 1990. 